\title{
Friction Expander for the Generation of Electricity (FEGE)
}

\author{
A. Kölling ${ }^{1}$, R. Lisker ${ }^{2}$, U. Hellwig ${ }^{3}$ and F. Wildenauer ${ }^{2}$ \\ ${ }^{1}$ ERK Eckrohrkessel GmbH \\ Am Treptower Park 28 A \\ 12435 Berlin - Germany \\ Phone/Fax number: +49 30897746 19, -46, e-mail: akoelling@eckrohrkessel.com \\ ${ }^{2}$ University of Applied Sciences Wildau \\ Hochschulring 1 \\ 15745 Wildau - Germany \\ ${ }^{3}$ La Mont GmbH \\ Beilsteiner Str. 119 b \\ 12681 Berlin - Germany
}

\begin{abstract}
At present and in future the necessity of generating electricity using renewable resources globally is most important and clearly evident. Depending on how the scenarios are designed and disregarding fossil resources the contributions of renewable energy sources have to be increased by a factor of four to six as far as it concerns the installed capacity and the amount of electricity generated. The corresponding annual investment costs amount some hundred billion US-\$ and the $\mathrm{CO}_{2}$ emission reduction equals one Gt. In any case heat to electricity conversion systems based on biomass, geothermal and process heat recovery are expected to provide significant contributions to this objective. Besides several others the conversion technology of a Rankine Cycle Process is most suitable over a wide range of capacities notwithstanding the possibilities to applicate working fluids of non-organic or organic character. Particularly for the heat recovery from the exhaust gas of biogas operated internal combustion engines the type of a newly developed friction expander was designed, constructed, built and evaluated. Based on preceding theoretical and numerical calculations as well as constructional and experimental studies using hexane and hexamethoxydisiloxane in the project reported here saturated water steam was used as working fluid. During the experiments carried out in a special test facility the electric power of the system amounted $1.4 \mathrm{~kW}$ representing two thirds of the concepttual design.
\end{abstract}

\section{Key words}

Friction Expander, Biogas CHP-Plant, Heat to Electricity, Lightweight Construction.

\section{Introduction}

Almost all of the energy system development scenario and technology assessment studies refer to time horizons between five and thirty-five years [1-4]. With respect to the generation of electricity and depending on the particular scenario the contribution of renewable energy sources in 2050 is expected to be increased by a factor of four to six compared to the level of 2010 which is equi-

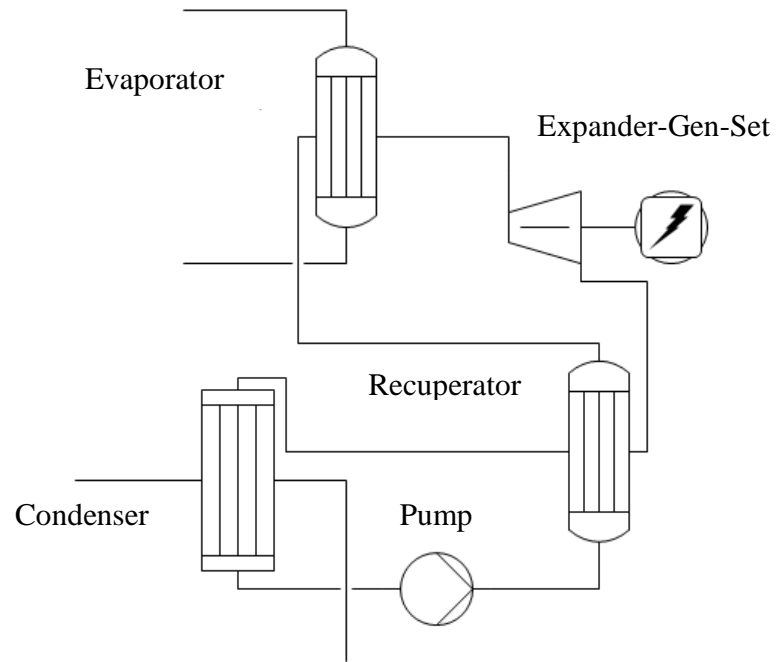

Fig. 1. Basic Configuration of a single stage ORC-process

valent to an installed electric capacity of 6-9 TW generating some 17-23 PWh, annually. The total investment costs within the next two decades are estimated to amount $62 \%$ in the power generation sector reaching almost $70 \%$ in 2035. In the EU 28 and on a shorter range the generation of electricity gained from renewable resources is predicted to be increased to $34.3 \%$ up to $43.3 \%$ depending on the particular scenario. At present the installed power of Organic Rankine Cycle (ORC) systems based on biomass, solar- and geothermal energy sources sharing $84 \%$ equals $1.3 \mathrm{GW}$ and is expected to be increased to some 6.0 $\mathrm{GW}$ in 2020 [5]. Because there are about 15000 biogas plant installations in Europe with an electric capacity of some $8 \mathrm{GW}$ in particular applications of ORC systems for the heat recovery from the exhaust gas of biogas operated internal combustion engines were focussed in this work [6]. A basic configuration of a single stage ORC-process with a recuperator working as preheater is shown in Fig. 1. In these cases the upper process temperature level equals 773 to $873 \mathrm{~K}$ while the ambient temperature level 
Table I. - Thermodynamic properties of some working fluids

\begin{tabular}{|c|c|c|c|c|c|}
\hline Symbol & \multicolumn{1}{|c|}{$\mathrm{M}$} & \multicolumn{1}{c|}{$\mathrm{p}_{\mathrm{C}}$} & $\mathrm{T}_{\mathrm{C}}$ & $\mathrm{C}_{\mathrm{p}, \mathrm{V}}$ & $\mathrm{C}_{\mathrm{p}, \mathrm{F}}$ \\
\hline Unit & $\mathrm{g}^{\prime} \mathrm{mol}^{-1}$ & \multicolumn{1}{c|}{$\mathrm{MPa}$} & $\mathrm{K}$ & $\mathrm{Jg}^{-1} \cdot \mathrm{K}^{-1}$ & $\mathrm{~J}^{-1} \mathrm{~K}^{-1}$ \\
\hline $\mathrm{H}_{2} \mathrm{O}$ & 18.0 & 22.1 & 647.1 & 1.943 & 4.22 \\
\hline $\mathrm{C}_{2} \mathrm{H}_{6}$ & 30.1 & 7.4 & 305.3 & 5.264 & 5.34 \\
\hline $\mathrm{CO}_{2}$ & 44.0 & 7.4 & 304.1 & 3.643 & - \\
\hline $\mathrm{C}_{4} \mathrm{H}_{10}$ & 58.1 & 3.8 & 425.1 & 1.966 & 2.31 \\
\hline $\mathrm{C}_{6} \mathrm{H}_{14}$ & 86.2 & 30.0 & 507.8 & 1.558 & 1.65 \\
\hline $\mathrm{C}_{6} \mathrm{H}_{18} \mathrm{O}_{7} \mathrm{Si}_{2}$ & 162.4 & 19.1 & 255.6 & 2.059 & 2.18 \\
\hline $\mathrm{C}_{6} \mathrm{H}_{18} \mathrm{O}_{7}$ &
\end{tabular}

$\mathrm{C}_{6} \mathrm{H}_{18} \mathrm{O}_{7} \mathrm{Si}_{2}$ - Hexamethoxydisiloxane, $\mathrm{V}$ - vapour, F - fluid

Table II. - Approximate technical risk potential estimation

\begin{tabular}{|c|c|c|c|c|c|}
\hline Symbol & F & ODP & GWP & HTP & ETP \\
\hline Unit & - & - & - & ppm & ppm \\
\hline $\mathrm{H}_{2} \mathrm{O}$ & no & 0 & n. e. & 0 & 0 \\
\hline $\mathrm{C}_{2} \mathrm{H}_{6}$ & yes & n. e. & 0 & n. e. & n. e. \\
\hline $\mathrm{CO}_{2}$ & no & 0 & 1 & $40000^{*}$ & n. e. \\
\hline $\mathrm{C}_{4} \mathrm{H}_{10}$ & yes & 0 & 0 & $5000^{*}$ & $500^{*}$ \\
\hline $\mathrm{C}_{6} \mathrm{H}_{14}$ & yes & n. e. & 0 & n. e. & $600^{*}$ \\
\hline $\mathrm{C}_{6} \mathrm{H}_{18} \mathrm{O}_{7} \mathrm{Si}_{2}$ & yes & 0 & 0 & n. e. & $1500^{*}$ \\
\hline $\mathrm{C}_{6} \mathrm{H}_{18} \mathrm{O}_{7} \mathrm{Si}_{2}$ - Hexamethoxydisiloxane, F - Flammability, OD \\
- Ozone Depletion, GW - Global Warming, HT - Human \\
Toxicity, ET - Eco-Toxicity, n. e. not estimated, * - \\
Threshold value \\
\hline
\end{tabular}

has a value of 273 to $308 \mathrm{~K}$. Besides this and according to the state of the art a classification of the thermodynamic properties and characteristics of appropriate fluids was made, complemented by an assessment of safety risks, environmental and health impacts as well as considerations of the principles for working fluid selection. Based on preceding theoretical and numerical calculations as well as constructional and experimental studies using hexane and hexamethoxydisiloxane the initial fluid classification and approximate technical risk potential estimation were made (Table I., II.) [7-18]. Although from the physical point of view ethane, hexane and hexamethoxydisiloxane would be favourable, the specific type of a friction expander is so robust and reliable that saturated water steam was preferred. Thereby the operational costs and the technical risk potentials could be minimized significantly.

Several different types of expanders and variants are discussed in the literature, besides the conventional axial types for example radial, centrifugal, scroll and screw expanders $[5,19]$. The efficiencies vary over a quite wide range and the resistance against blade erosion just as well to such an extent that the choice of the specific type of expander tends to dominate the whole conceptual design. This results from the characteristic of the working fluid, because only that ones with dry or isentropic expansion into the unsaturated region of the state function without condensation in the expander are non-corrosive and thereby do not cause any stress or damage of the blades.

In principle this can be avoided using a tangentially perfused expander with plan-parallel discs coaxially arranged on a rotational shaft with a fluid outlet at its center. Because the gaps between the discs are of the order of the adhesive boundary layer the working fluid flows on a spiral way through the expander thereby accelerating the system and is leaving it through the outlet. Such continuous-flow machines driven by intense shear stress are connoted as friction expander or Tesla turbine (Fig. 2).

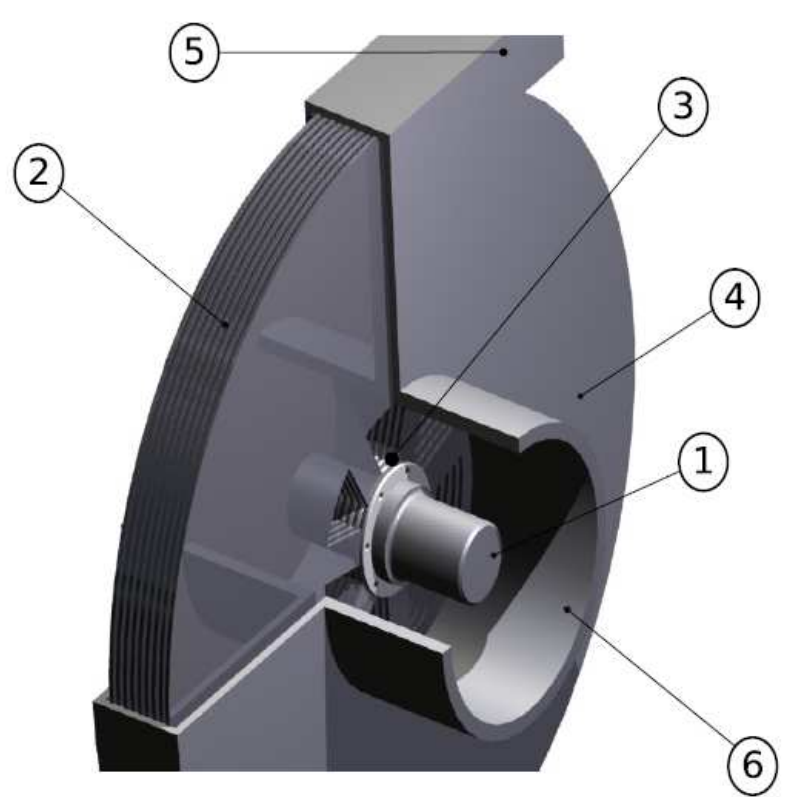

Fig. 2. 8-blade Friction Expander ((schematic), 1 - Shaft, 2 Blades, 3 - Spacer, 4 - Shell, 5 - Inlet, 6 - Outlet).

\section{Friction Expander}

The basic idea of a friction expander follows the Newtonian concept of viscous flow. The model implies that the free or forced flow takes place being restricted by a wall near boundary layer due to adhesion. It states that an idealised laminar stream is characterised by a local shear stress proportional to a substance specific dynamic viscosity coefficient and the effective rate of sheer. In the consequence a friction force gradient evolves merging to the wall near boundary layer resulting from the static friction between the fluid and the blade. Quantitatively the shearing force depends on the velocity gradient, the viscosity of the fluid and area of the blade being equal to:

$\mathrm{F}_{\mathrm{s}}=\eta \frac{\partial \mathrm{w}}{\partial \mathrm{z}} \mathrm{A}$

By means of the transferred momentum it is possible to propel a rotational machine of the Tesla type effectively. To do this several kinds of gases, e. g. flue or exhaust gases, vapours of water and other working fluids, and, less well, liquid substances can be used. The inflow of the working medium takes place tangentially, the throughflow in radial direction with decreasing distance from the centre and the outflow in axial direction (Fig. 3).

To put it into practise, an open throughput process or a closed Clausius-Rankine Process, short Rankine Process, in the case of water or an Organic Rankine Process in
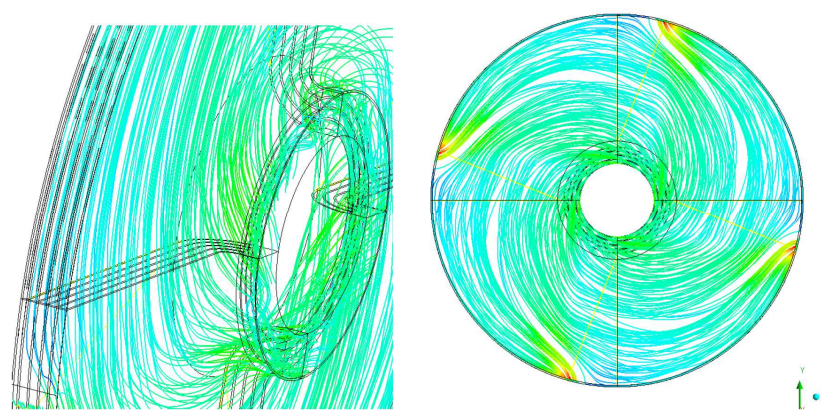

Fig. 3. Streamlines of fluid flow at four inlet nozzles (r.) and in the outlet region (Computational Fluid Dynamics). 


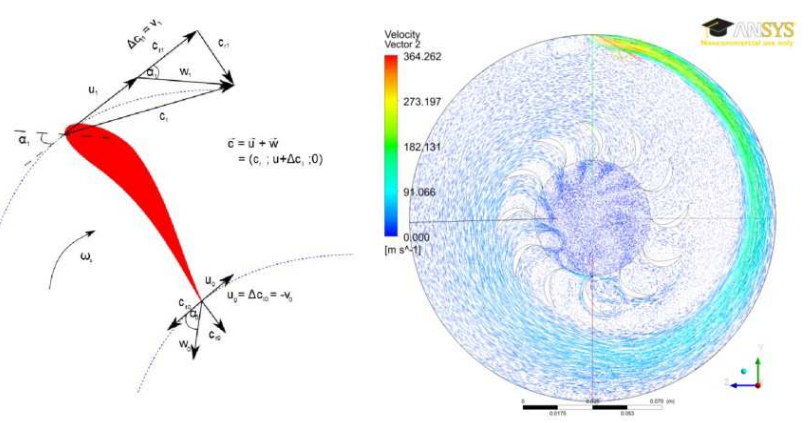

Fig. 4. Velocity components at an outlet profile (1.), field plot.

cases of n-Hexane, Hexamethoxydisiloxane or others is realised, which were used for comparative studies. At present and in particular it is of certain interest to recover exhaust gas heat of biogas driven internal combustion engines to evaporate and superheat water steam which is expanded to run a friction turbine coupled to an electric generator feeding the electricity to the grid or utilise it onsite. In general terms there is seen a wide range of applications in the fields bioenergy, geothermal energy as well as heat recovery in almost any area of industry, energy and process technology.

\section{A. Basic Design and Engineering}

The aim of the work was to develop a suitable construction of a prototypic, stepwise scalable friction expander-gen-set with an electric capacity of $1 \mathrm{~kW}$ to $50 \mathrm{~kW}$ superficially being used for biogas CHP-plants, build and evaluate its sterling quality by experiments. The scaling was carried out using the method of normalized number sequence referenced to the number 40 with 7 steps resulting in series of capacities amounting to 1, 2.2, 15, 25 and $50 \mathrm{~kW}$. State of art is the application of expensive and less effective screw and turbo compressors which should be substituted by a low-cost, reliable and efficient friction expander. Based on theoretical and numerical calculations taking into account production engineering and cost constraints several design variants were projected, built und studied.

For the basic engineering an own software tool was used based on the definite thermodynamic and geometric input parameters. It was referred to a $2.2 \mathrm{KW}$-prototype with a water steam mass flow of $0.02 \mathrm{~kg} \cdot \mathrm{s}^{-1}$ at $1 \mathrm{MPa}$ and 593 $\mathrm{K}$. Consequently eight blades were made using steel No. 1.4301 similar to ASME 304 or UNS S30400 with 1.5 $\mathrm{mm}$ thickness, $175 \mathrm{~mm}$ diameter and $0.5 \mathrm{~mm}$ spacing.

\section{B. Detail Engineering}

Intense care was taken regarding the construction of the in- and outlet and several numerical calculations were carried out varying process conditions and geometries. In order to achieve maximal mass flow value and homogeneous distribution the cross section of the tangential inlet was shaped rectangular with a very small gap between the two nozzles and rotor designed for velocities in the range of $200 \mathrm{~m} \mathrm{~s}^{-1}$. To avoid losses of kinetic energy the outer discs were dimensioned slightly larger in diameter to inhibit leak flows into pitch between rotor and shell. Having past the inlet the working fluid expands progresssively in the decreasing flow section reaching the

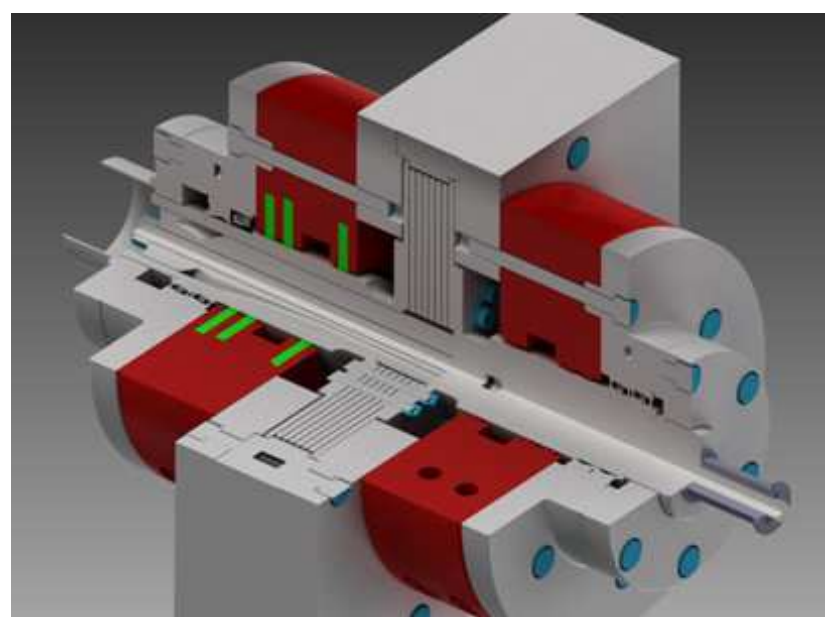

Fig. 5. 3D-Expander-Model with coal swimming rings ( $\square$ ) and seal ( $\square)$.

maximal tangential and radial velocity at the center before being ejected in perpendicular direction through the outlet. Balancing of momentum results in a relation of mechanical power (Fig. 4):

$\mathrm{P}_{\text {mech }}=\dot{\mathrm{m}}\left(\mathrm{c}_{1} \mathrm{u}_{1}-\mathrm{c}_{0} \mathrm{u}_{0}\right)$

The velocities $u$ of the discs and $\mathrm{c}$ of the fluid at the inlet (1) and outlet (0) should be justified in a way, that $\mathrm{c}_{0}$ becomes small to get maximal $\mathrm{P}_{\text {mech }}$. Therefore a circular arrangement of six wing-shaped deflecting profiles was installed at the bottom of the discs.

The working fluid leaves the rotor through a hollow shaft, but, because of inertia, an angular momentum is transferred from the rotor to the fluid flow, thereby forcing it in the direction of the shaft. To avoid partial reverse flow and vertebration resulting from the negative pressure, definite detail constructions of the slightly conical outlet and a tubular profile device to reset the shaft were developed and applied to minimize fluid dynamic losses. The sealing of the rotor was managed using coal swimming rings because of the superior hermeticity. Taking the absolute isentropic efficiency being the ratio of the difference in enthalpy of the irreversible expansion rate and reversible expansion rate at given steam pressure inand output:

$\eta_{\text {isen }}=1-\left(\frac{p_{S, i}}{p_{\text {S.o }}}\right)^{\frac{\kappa-1}{\kappa}}$

the comparative efficiency can be expressed by:

$$
\eta_{\text {isen }}=\frac{\mathrm{h}_{\mathrm{T}, \mathrm{p}, \mathrm{i}}-\mathrm{h}_{\mathrm{T}, \mathrm{p}, \mathrm{o}}}{\mathrm{h}_{\mathrm{T}, \mathrm{p}, \mathrm{i}}-\mathrm{h}_{\mathrm{T}, \mathrm{p}, \mathrm{id}}}
$$

\section{System Integration}

Finally all of the components of the single stage ORC system without preheater were integrated - the evaporator, xxpander, condenser and the feed water pump. The evaporator was a DINO CD45K boiler with integrated feed water pump without preheater, special constructed, noncommercial super-heater and condenser and an electric generator Siemens 1FT5074three-phase motor with incremental transmitter ROD320. The net power of the system is determined by the mass flow, the related enthalpy gradient and the efficiency of each of the components [20]:

$\mathrm{P}=\sum_{\mathrm{i}} \dot{\mathrm{m}}_{\mathrm{i}} \Delta \mathrm{h}_{\mathrm{i}} \eta_{\mathrm{i}}$ 


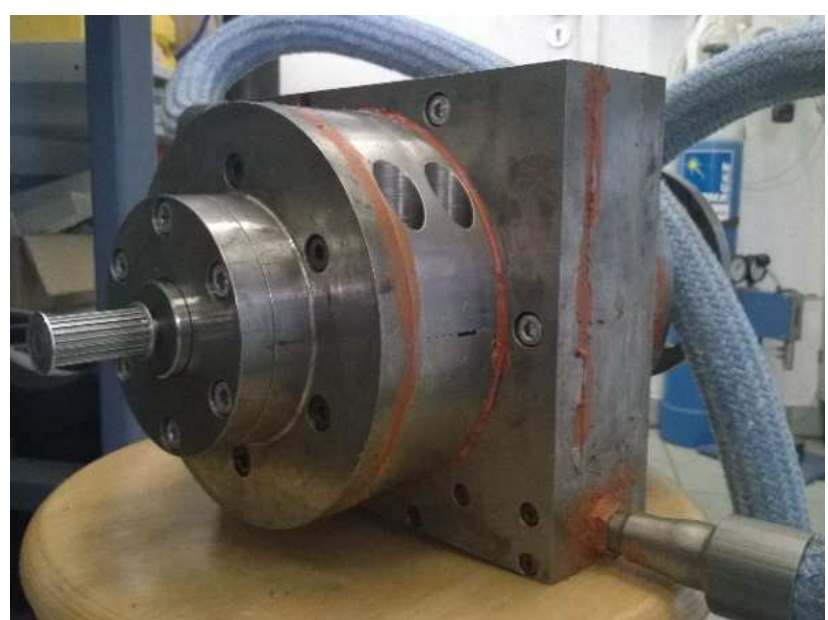

Fig. 6. Integration of the expander-gen-set.

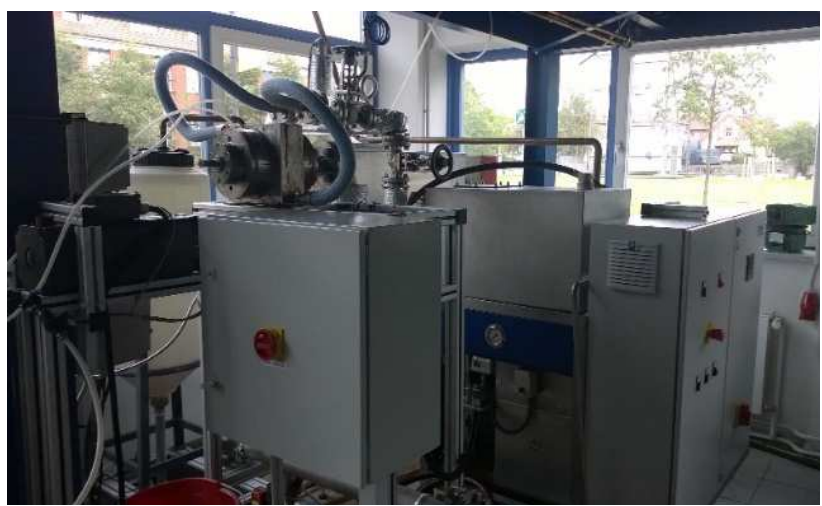

Fig. 7. Experimental set-up at the test facility.

\section{Experimental Set-up}

Each of the components was equipped with measurement devices detecting input, output and, whenever necessary and suitable, performance data. A computer configurated with LABVIEW-software was used for the visualization, recording and controlling. The steam mass flow was measured by means of a Vortex flow meter. Temperature measurement were carried out using Ahlborn FPA32L0100 + OPG5 Pt100 thermocouples with a range of 73.75 to $673.15 \mathrm{~K}$ and an accuracy of +/- $0.2 \mathrm{~K}$. Pressures were detected by JUMO 40-4304 membrane pressure gauges and transducer with a resolution of $1 \mathrm{~Pa}$. Rotation rates were determined using Ahlborn FUA9192 optical revolution number sensor with an exactness of $1 \mathrm{~s}^{-1}$. Ambient conditions were controlled by standard equipment.

The measurement campaign was executed by systematic variations of steam pressure and mass flow. Overall, four series with thirty-five steady state measurements were made testing the expander with and without blade profiles as well as the conventional and the modified shaft.

\section{Results}

From a broad point of view the expander generated maximal $1.4 \mathrm{~kW}$ electric power which equals two thirds of the nominal load if operated with the specific modifications and saturated water steam at 9 bar and $0.11 \mathrm{~kg} \cdot \mathrm{s}^{-1}$. The conventional type is about $20 \%$ lower of which one third is ascribed to the lack of blade profiles and two thirds to the conventional design of the shaft (Fig. 8a,b). The isen-

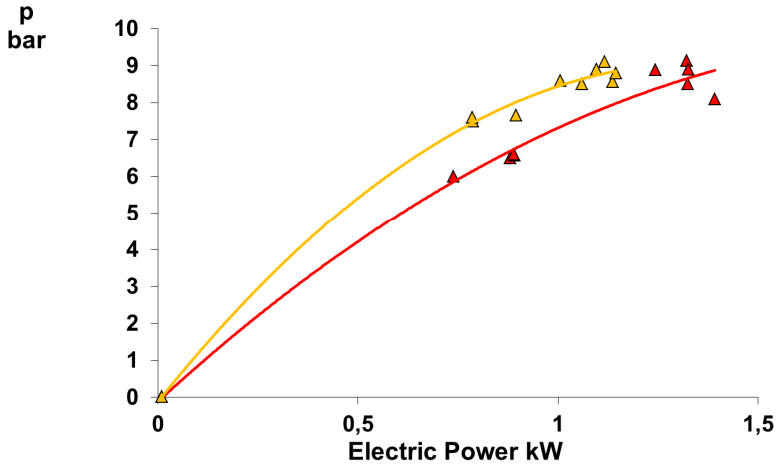

Fig. 8a. Electric power varying water steam pressure.

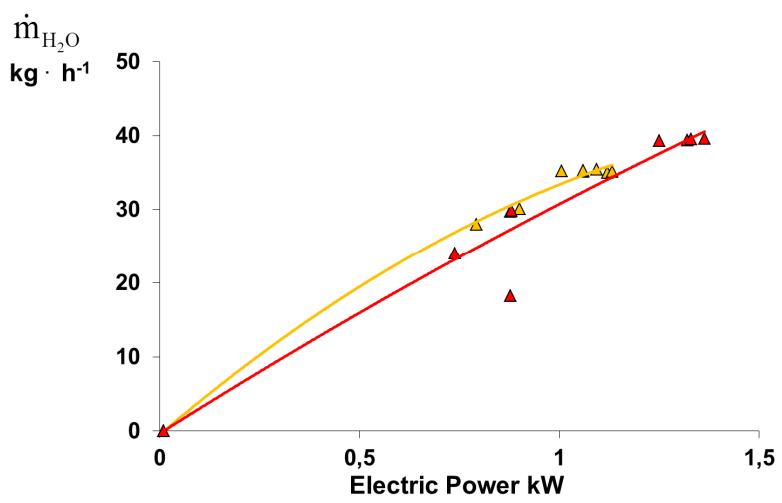

Fig. 8b. Electric power varying water steam mass flow.

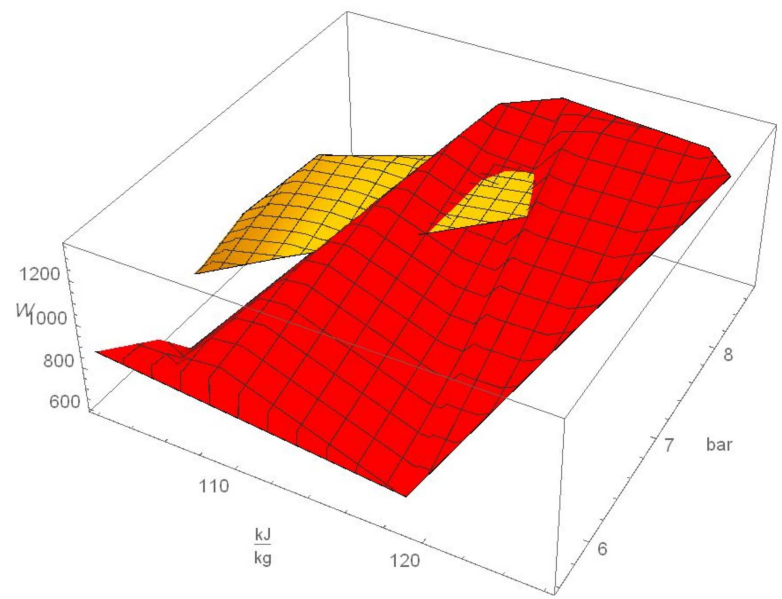

Fig. 8c: Characteristic values of electric power varying enthalpy flow and pressure of the two configurations ( $\square$ modified expander, $\square$ conventional).

tropic efficiency according to Eq. 4 is then 0.3 and 0.27 , respectively. Taking the specific enthalpy of water steam amounting $2773.04 \mathrm{~kJ} \cdot \mathrm{kg}^{-1}$ and the resulting enthalpy input flow to be $305.03 \mathrm{~kJ} \cdot \mathrm{s}^{-1}$, at present the term of the absolute total efficiency of the component according to Eq. 5 would be about 0.005 . These findings were synthesized to get a more generalized 3D-plot of the characteristic values of electric power varying enthalpy flow and pressure of the two configurations (Fig. 8c).

Although the distribution of the measured values at the first glance may seem a little scattered the resulting best fit functions appear to be a $2^{\text {nd }}$ order polynom. In any case the measure of determination calculated, using the Newtonian method of least square fit, is larger than $R^{2}=0.98$, except the mass stream of the modified expander which is $\mathrm{R}^{2}=0.93$. 


\section{Conclusion}

Starting from previously obtained results of theoretical and numerical calculations as well as constructional and experimental studies a new prototypic friction expander, connoted as Tesla turbine, was designed, constructed built and evaluated successfully. By experiments it was shown that specific measures of improvement by means of blade deflection profiles, conical outlet and reset-profile of the shaft in fact increase the electric power output to a value of $1.4 \mathrm{~kW}$ and the isentropic efficiency by $10 \%$, representing two thirds of the nominal load of $2.2 \mathrm{~kW}$. At present driven by saturated water steam as working fluid, in future the friction expander will be operated successsively with super-heated steam of water, hexane, cyclopentane und ethanol. Moreover it is planned to scale up the expander to an electric capacity of 15,25 and $50 \mathrm{~kW}$ and improve its basic and detail engineering. Assuming, due to theoretical considerations and empirical experience, that super-heated ethane steam and exhaust gas at $823 \mathrm{~K}$ are used in addition to further improvements, e. g. perfect hermeticity, expander modifications, thermal isolation, generator equipment, and taking into account effects of economy of scale, then a net electric efficiency of the order of $0,2=\eta_{\text {el,net }}$ is achievable by the application of the developed friction expander to generate electricity using the heat of the exhaust gas emitted by biogas driven internal combustion engines. Finally it is usual to carry out field tests elsewhere in a suitable environment and integrated into different commercial biogas operated combined heat and power plants.

\section{Acknowledgement}

German Federal Ministry for Economic Affairs and Energy.

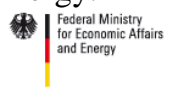

\section{References}

[1] R. Whitney, World Energy Scenarios - Composing Energy Futures to 2050, World Energy Council, http://www.worldenergy.org/publications/2013/worldenergy-scenarios-composing-energy-futures-to-2050/, London, United Kingdom, accessed 12. 1. 2015.

[2] M. van der Hoeven, World Energy Outlook 2014, International Energy Agency, ISBN 978-92-64-20804-9, Paris, France.

[3] A. Zervos, C. Lins, L. Tesnière, E. Smith, Mapping Renewable Energy Pathways towards 2020 - EU Roadmap, European Renewable Energy Council, Bruexelles, Belgium, http://www.beeev.de/_downloads/publikationen/sonstiges/ 2011/1103_EREC-roadmap.pdf, accessed 12. 1. 2015.

[4] A. Rettig, M. Lagler, T. Lamare, S. Li, V. Mahadea, S. McCallion, J. Chernushevich, "Applications of Organic Rankine Cycles", in Proc. World Engineers Convention, WEC-7-30, Geneva, 4-9 September, Switzerland 2011.

[5] S. Quoilin, M. Van Den Broek, S. Declaye a, P. Dewallef, V. Lemort, Techno-economic survey of Organic Rankine Cycle (ORC) systems, Renewable and Sustainable Energy Reviews 22(2013) pp. 168-186.

[6] European Biogas Association, Biogas Statistics, http://euro-pean-biogas.eu/wp-content/uploads/2014/12/

Biogas-graph-2013.png, assessed 14. 1. 2015.

[7] C. Holz, Ansätze zur serientechnischen Auslegung von Tesla-Turbinen, Bachelor Thesis, University of Applied Sciences Wildau, Germany 2014.

[8] M. Robert, Strömungstechnische Untersuchung der Eintritts- und Austrittsströmung an einer Scheibenturbine, Bachelor Thesis, University of Applied Sciences Wildau, Germany 2013.

[9] T. Pannasch, Auslegung und Entwurf einer Teslaturbine einschließlich einer Leistungsmesseinrichtung, Diploma Thesis, University of Applied Sciences Wildau, Germany 2011.

[10] H. Sagasser, S. Schröder, Verstromung von Abwärme in kleinen Leistungsbereichen, Diploma Thesis, University of Applied Sciences Wildau, Germany 2010.

[11] R. Lisker (2009) Numerische Strömungsuntersuchungen an einer Tesla Turbine, Diploma Thesis, University of Applied Sciences Wildau, Germany 2009.

[12] A. F. Rey Ladino, Numerical Simulation of the Flow Field in a Friction-Type Turbine, Diploma Thesis, Institute of Thermal Powerplants, Vienna University of Technology, Austria 2004.

[13] B. E. Poling et al., Perry's Chemical Engineers Handbook, 8th Ed., The McGraw-Hill-Companies Inc., Columbus, USA (2011), pp. 2-1 - 2-516, DOI:10.1036/0071511253.

[14] A. Guha, S. Sengupta, The fluid dynamics of the rotating flow in a Tesla disc turbine, European Journal of Mechanics - B/Fluids 37(2013), pp. 112-123.

[15] A. Algieri, P. Morrone, Comparative energetic analysis of high-temperature subcritical and transcritical Organic Rankine Cycle (ORC), Applied Thermal Engineering 36(2012), pp. 236-244.

[16] H. Tian et al., Fluids and parameters optimization for the organic Rankine cycles (ORCs) used in exhaust heat recovery of Internal Combustion Engine (ICE), Energy 47(2012), pp. 125-136.

[17] A. Schuster et al., Energetic and economic investigation of Organic Rankine Cycle applications, Applied Thermal Engineering 29(2009), pp. 1809-1817.

[18] J. Facao, A. Oliviera, "Analysis of energetic, design and operational criteria when choosing an adequate working fluid for small ORC systems", Proc. ASME IMECE 2009, IMECE 2009-12420.

[19] J. Hampel, Getriebefreie Kleindampfturbine, VGB Power Tech 4(2008)14, pp. 75-80.

[20] J. H. Horlock, Cogeneration - Combined Heat and Power, Krieger Publishing Company, Malabar, Florida, USA 1997. 